Neurosurg Focus 19 (3):E6, 2005

\title{
Embryonic stem cell-derived astrocytes: a novel gene therapy vector for brain tumors
}

\author{
Mahmud Uzzaman, M.D., Ph.D., Ronald J. Benveniste, M.D., Ph.D., \\ Gordon Keller, Ph.D., ANd Isabelle M. Germano, M.D.
}

Departments of Neurosurgery and Gene and Cell Medicine, Mount Sinai School of Medicine, New York, New York

\begin{abstract}
Object. For gene therapy strategies currently in clinical trials, viral vectors are used to deliver transgenes directly to normal and tumor cells within the central nervous system (CNS). The use of viral vectors is limited by several factors. The aim of this study was to assess whether embryonic stem cell (ESC)-derived astrocytes expressing a doxycyclineinducible transgene can be used as a vector for gene therapy.

Methods. The authors generated a pure population of ESC-derived astrocytes carrying a transgene, tumor necrosis factor-related apoptosis-inducing ligand (TRAIL), inserted in the chromosome under the control of a highly regulated doxycycline-inducible expression system. Fully differentiated ESC-derived astrocytes were stereotactically transplanted in the mouse brain, and then cell migration and transgene expression were studied.

Results. The ESC-derived astrocytes started to migrate from the transplant site 48 hours after the procedure. They were found to have migrated throughout the brain tissue by 6 weeks. Transplanted ESC-derived astrocytes expressed the TRAIL transgene after doxycycline induction throughout the duration of the experiment. Teratoma formation was not observed in long-term experiments (12 weeks).

Conclusions. These data show that ESC-derived astrocytes can be used as delivery vectors for CNS tumors. This technique might have a major impact on the treatment of patients with malignant gliomas and a wide spectrum of other neurological diseases.
\end{abstract}

\section{KEY WORDS - embryonic stem cell • astrocyte - gene therapy - malignant glioma $\bullet$ tumor necrosis factor-related apoptosis-inducing ligand $\bullet$ mouse}

Malignant gliomas are the most common primary brain tumors in adults. The prognosis for survival in patients with malignant gliomas is still only 1 year after diagnosis, even with the most aggressive surgical, radiation, and chemotherapeutic treatments. ${ }^{44}$ New strategies focused on targeting brain tumor cells while sparing normal tissue include cell and/or gene therapy approaches. Although chemotherapy has been incorporated into the treatment of various intracranial neoplasms, the resistance and invasive nature of these tumors compel us to find a new strategy for treatment.

For gene therapy strategies currently being tested in clinical trials, viral vectors are used to deliver therapeutic transgenes directly to normal and tumor cells within the CNS., ${ }^{8,13}$ Viral vectors, however, have a number of theoretical and practical limitations, including limited diffusion into brain parenchyma, poor transfection, antigenicity, and risk of potential insertional mutagenesis with formation of new tumors. ${ }^{20,37}$ The use of genetically modified cells to deliver gene therapy to the CNS may avoid some of these limitations. ${ }^{12}$

Abbreviations used in this paper: $\mathrm{BMSC}=$ bone marrow stem cell; cDNA = complementary DNA; CNS = central nervous system; $\mathrm{ESC}=$ embryonic stem cell; hTRAIL = human tumor necrosis factor-related apoptosis-inducing ligand; NSC = neural stem cell; RT-PCR $=$ reverse transcription-polymerase chain reaction.
Astrocytes are native to the CNS, which should maximize their survival and function after transplantation. Astrocytes are a highly secretory cell type that are able to generate large amounts of transgenic protein. ${ }^{2,11}$ Therefore, transplanted astrocytes should be protective within the host brain. ${ }^{38}$ Finally, normal astrocytes have the ability to migrate along white matter tracts after transplantation into the brain. ${ }^{16,17,42}$ This migratory capacity may be useful for delivery of gene therapy to infiltrative tumors like malignant gliomas.

Astrocytes could be obtained from a number of different sources. Autologous samples from the pluripotent neural precursors in the ventricles or from fetal tissue could provide some astrocytes for transplantation. These approaches are hazardous, and their capability of generating sufficient numbers of cells is limited. The use of ESCs could provide an alternative source of astrocytes that overcome these difficulties. The aforementioned cells are totipotent types that are obtained from the inner cell mass while in the blastocyst stage and have the capacity to differentiate into any cell in the body. ${ }^{24,28,29,33,45}$ Our recent work shows that we can generate a pure population of astrocytes from mouse ESCs and that these cells express transgene under doxycycline control while minimizing contamination by potentially hazardous, undifferentiated ESCs. ${ }^{7}$

A member of the tumor necrosis factor family, TRAIL 
has been shown to induce apoptosis in a variety of transformed cell lines and still spare most normal cells.,21,23 Transduction by adenoviral vector expression of hTRAIL cDNA (Ad.TRAIL-GFP) resulted in direct tumor cell death as well as a potent effect through presentation of TRAIL by transduced normal cells. Administration of Ad.TRAIL-GFP significantly prolonged survival of mice harboring intracerebral glioblastomas. ${ }^{39}$ Systemic administration of recombinant TRAIL protein was associated with minimal toxicity in recent clinical trials for tumors other than brain lesions.

Our recent work shows that we can generate a pure population of transgenic ESC-derived astrocytes with a highly regulated, robust conditional expression of TRAIL under the control of a tetracycline-inducible promoter that induces tumor cell death in vitro (unpublished data). Based on our recent work, we hypothesize that ESC-derived, doxycycline-inducible, TRAIL-expressing astrocytes may represent an effective and novel approach for treatment of human malignant gliomas. To our knowledge this is the first report of transgene-expressing ESC-derived astrocytes as a gene delivery vector in brain tissue.

\section{MATERIALS AND METHODS}

\section{Cell Lines and Culture}

The Ainv-18 embryonic stem cells (gift of Dr. Michael Kyba, University of Texas Southwestern Medical Center, Dallas, TX) constitutively express a doxycycline-binding transcriptional activator fusion protein and include a doxycycline-responsive promoter upstream of a Lox cloning site. ${ }^{25}$ Genes cloned into the Lox site using Cre-assisted recombination ${ }^{41}$ are then expressed when the cells are exposed to doxycycline. Mouse ESCs were passaged and maintained according to previously published protocols, and these cells were then directed to differentiate into astrocytes by using protocols recently developed in our laboratory. ${ }^{7}$

\section{Construction of Ainv-hTRAIL ESCS}

A cDNA containing the entire coding sequence of hTRAIL (gift of Dr. Bingling Fang, MD Anderson Cancer Center, Houston, TX ${ }^{22}$ was cloned into the pLox vector (gift of Dr. Kyba) ${ }^{25}$ and sequenced at the Mount Sinai School of Medicine Core Sequencing Facility. The hTRAIL-pLox plasmid DNA and Cre recombinase-expressing helper plasmid DNA were prepared using a column purification system (Qiagen, Valencia, CA) and electroporated into appropriately prepared Ainv-18 mouse ESCs. Electroporated Ainv-18 cells were plated onto drug-resistant embryonic feeder cells, and recombinant clones were selected using increasing concentrations of G418. Individual G418-resistant colonies were selected and expanded. Insertion of transgene into the Lox cloning site was confirmed using PCR from a genomic DNA template. (Forward primer: 5'-GTG GCT GTA ACT TAC GTG TA-3'; reverse: 5'-TTG ATA GAT GGA ATA GAG TC-3'; conditions: 35 cycles, 2 -minute $95^{\circ} \mathrm{C}$ denature; 15 -second $95^{\circ} \mathrm{C}$ denature; 30 -second $60^{\circ} \mathrm{C}$ annealing; 60 -second $72^{\circ} \mathrm{C}$ extension; 10 -minute $72^{\circ} \mathrm{C}$ elongation.)

\section{Analysis of Gene Expression and RT-PCR}

The Ainv-hTRAIL ESCs or astrocytes were cultured for 24 hours in the presence or absence of $1 \mu \mathrm{g} / \mathrm{ml}$ doxycycline (Sigma Chemical Co., St. Louis, MO) and harvested for RT-PCR assays. Total cellular RNA from cultured cells was purified using the RNeasy kit (Qiagen), with one-column DNAse treatment. All RNA preparations were spectrophotometrically quantified and examined for degradation by using gel electrophoresis prior to RT. The RT was performed on $1 \mu \mathrm{g}$ of total RNA by using the Omniscript kit (Promega, Madison, WI) and PDN6 random hexamer primers (Pharmacia, Piscataway, NJ) in a total volume of $20 \mu \mathrm{l}$. The $12.5-\mu \mathrm{l}$ PCR mixtures each contained $0.5 \mu \mathrm{l}$ of cDNA template. All PCR amplifications were performed for 35 cycles. The PCR products were examined on $1.8 \%$ agarose gels and photographed using an Eagle Eye II imager (Stratagene, La Jolla, CA). Each experiment was repeated three times.

\section{Experimental Animals and Surgical Techniques}

Female C57BL7 mice from Taconic (Germantown, NY) weighing 60 to $90 \mathrm{~g}$ were used for the cell implantation experiments. The mice were housed in standard facilities and given free access to food and water. The experimental protocol was approved by the Institutional Animal Care and Use Committee of the Mount Sinai School of Medicine and met all federal guidelines. For induction of TRAIL, animals were allowed to drink freely of doxycycline-containing water (20 $\mu \mathrm{g} / \mathrm{ml})$ up to the day of planned death.

Stereotactic cell implantation is described elsewhere. ${ }^{8}$ Briefly, mice were anesthetized with intraperitoneal ketamine-xylazine $(5 \mathrm{mg} / \mathrm{kg})$. After supplementation of local anesthesia with buprenorphine (0.03 $\mathrm{mg} / \mathrm{kg}$ ), a linear scalp incision was made, followed by bilateral burr holes located at the entry point of the stereotactic injection. The animals were then positioned in a stereotactic frame (Stoelting Co., Oak Dale, IL). Target selection was made using a standard mouse brain atlas. $^{34}$ For the striatum, coordinates were $0.62 \mathrm{~mm}$ anterior to the bregma, $2 \mathrm{~mm}$ lateral, and $3.5 \mathrm{~mm}$ deep to the cortical surface. For the corpus callosum, coordinates were $0.62 \mathrm{~mm}$ anterior, $2 \mathrm{~mm}$ lateral, and $2.5 \mathrm{~mm}$ deep. Cells were transplanted as described later.

At least three animals were examined at each of the following time points: 24 hours, 48 hours, 7 days, 3 weeks, and 6 weeks after transplantation. In addition, to rule out the presence of teratoma, four animals were allowed to survive for 12 weeks after transplantation.

Expression of TRAIL in ESC-Derived Astrocytes in the Mouse Brain: Cell Transplantation Techniques

The ESC-derived astrocytes were trypsinized, washed with Iscove modified Dulbecco medium plus $15 \%$ fetal calf serum, and resuspended in medium $\left(3 \times 10^{4}\right.$ cells $\left./ \mu \mathrm{l}\right)$. Cell viability was checked using eosin and cells were labeled using a PKH26 cell linker kit (Sigma Chemical Co. $)^{20,36}$ before implantation, according to the protocol outlined in the product data sheet. Cells were then loaded into a Hamilton syringe with a 21-gauge hypodermic needle fitted coaxially over the distal portion of the needle to avoid its deflection, and a $25-\mu 1$ volume of cell suspension $\left(10^{4}\right.$ cells) was injected into the right hemisphere. The injection rate was $5 \mu \mathrm{l} /$ minute, allowing an additional 2 minutes after completion of the injection for pressure equilibration prior to slow withdrawal of the needle. A sham injection of Iscove modified Dulbecco medium without ESC-derived astrocytes was made into the left hemisphere for each animal. Incisions were closed with 3-0 nylon sutures, and the animal was allowed to recover on a warming blanket. Following transplantations, the remaining cells in the Hamilton syringe were recovered and cultured to confirm viability.

\section{Histological, Immunohistochemical, and Brain Tissue Analysis}

At each time point, animals were killed and their brains examined for cell viability and migration. To accomplish this, the animals were anesthetized with intraperitoneal ketamine-xylazine, and then perfused intracardially with cold $4 \%$ paraformaldehyde in phosphatebuffered saline. Brains were then removed whole and postfixed with $4 \%$ paraformaldehyde in phosphate-buffered saline at $4^{\circ} \mathrm{C}$ for 48 hours. After identification of the needle entry point on the brain surface, the brains were embedded in Tissue Tak and sliced in the coronal plane in $10-\mu \mathrm{m}$-thick frozen sections. Ten sections were taken in front and 10 in back of the point of injection. Alternating sections were either stained with $\mathrm{H} \& \mathrm{E}$ or processed for immunohistochemistry in appropriate experiments.

For immunocytochemical studies, differentiated cells were grown on glass cover slips (Fisher Scientific, Hampton, NH) coated with poly-D-lysine (Sigma Chemical Co.). For immunofluorescent labeling, cells were washed with phosphate-buffered saline, fixed in $4 \%$ paraformaldehyde in phosphate-buffered saline for 30 minutes at room temperature, washed again, preincubated in $10 \%$ normal goat serum (Sigma Chemical Co.) for 30 minutes at room temperature, then in primary antibody for 1 hour at room temperature. Primary antibodies and dilutions were as follows: monoclonal anti-glial fibril- 
lary acidic protein, 1:200 (Sigma Chemical Co.) and monoclonal anti-TRAIL, 1:200 (Chemicon International, Inc., Temecula, CA). Alexa 488 anti-mouse antibody (1:400) was used as a secondary antibody. Cells were then washed and mounted in Vectashield with added 4,6'-diamino-2-phenylindole-dihydrochloride (Vector Laboratories, Burlingame, CA), and examined under fluorescent microscopy by using the Openlab imaging system (Improvision, Lexington, MA). Omission of the primary antibody served as a negative control.

\section{RESULTS}

\section{Expression of TRAIL by ESC-Derived Astrocytes Under Doxycycline Control}

Expression of the inserted TRAIL transgene was assayed using RT-PCR and immunohistochemistry in ESC-derived astrocytes. The RT-PCR analysis (Fig. 1A) showed a readily detectable TRAIL expression 24 hours after doxycycline induction. The TRAIL expression was confirmed by immunohistochemistry findings (Fig. 1B and C). These data confirm that ESC-derived astrocytes express the TRAIL transgene in vitro under the control of a doxycycline-sensitive promoter.

\section{Migration of ESC-Derived Astrocytes After Transplantation Into the Mouse Brain}

Coronal brain sections analyzed using a fluorescent microscope showed that 24 hours after the transplantation, cells appeared as a clump at the needle insertion site (Fig. $2 \mathrm{~A}$ and $\mathrm{B})$. Forty-eight hours after transplantation, ESC-derived astrocytes gradually started to migrate to the surrounding tissue (Fig. 2C and D). These data show that ESCderived astrocytes are viable and retain their migratory capacity in the host tissue. Transplanted cells were found in the opposite cerebral hemisphere at 6 weeks (Fig. 2E and F). Migratory ESC-derived astrocytes were found in white and gray matter.

Analysis of serial sections obtained in the brains of mice allowed to survive for 12 weeks after ESC-derived astrocyte transplantation did not show the presence of teratoma.

\section{Expression of TRAIL by Transplanted ESC-Derived Astrocytes Under Doxycycline Control}

To confirm the ability of the ESC-derived astrocytes to sustain transgene expression after transplantation, we administered doxycycline to the mice. Forty-eight hours after transplantation, TRAIL-positive cells were seen at the implant site (Fig. 3A and B). The TRAIL-positive cells were not observed when TRAIL antibody was omitted or doxycycline was not administered to the mice (Fig. 3C). Similar results were recorded at the other time points. These data confirm that conditionally expressing ESC-derived astrocytes maintain their ability to express transgene under doxycycline control in vivo.

\section{DISCUSSION}

The ESC-Derived Cells as Gene Therapy Vectors for CNS Tumors

Several types of cells have been suggested as gene therapy vectors for diseases of the CNS, including autologous $\mathrm{BMSCs}^{26}$ or NSCs from the subventricular zone. ${ }^{10,20,24,32,35,43}$
Previously published studies in animal models show that these cell types are promising gene therapy vectors, with good engraftment and survival in the host brain, a favorable safety profile, and in many cases, the ability to "track" tumor cells within the brain parenchyma. ${ }^{1,6,30}$ Currently, however, the restricted proliferative capacity of differentiated neural cell types ${ }^{16}$ and the need to transfect them with viral vectors to express therapeutic genes have hindered the use of these cells. ${ }^{17}$

We suggest that ESC-derived cells may have unique characteristics that provide advantages over other cell types for gene therapy of CNS tumors. First, the use of autologous NSCs or BMSCs requires a separate harvesting procedure (including an intracranial procedure in the case of NSCs) as well as time-consuming and expensive ex vivo expansion, transgene insertion, and directed differentiation, which would have to be conducted separately for each patient. In contrast, the unlimited proliferative capacity of ESCs could allow the maintenance of stocks of transgenic, predifferentiated cells for allotransplantation. Second, transgene insertion into BMSCs or NSCs generally requires the use of viral or episomal vectors, which can result in short-lived transgene expression, host immune responses, or insertional mutagenesis. ${ }^{20,27}$ In contrast, transgenic constructs can be permanently and clonally inserted into ESCs by using homologous recombination, resulting in large stocks of genetically homogeneous cells with predictable transgene expression. ${ }^{7}$

In this study we describe sustained expression of a druginducible transgene after allotransplantation of ESC-derived astrocytes. Although formation of teratomas has been observed following transplantation of undifferentiated ESCs in rodent and primate models, ${ }^{3,15}$ transplantation of sufficiently differentiated populations of ESC-derived cells appears to minimize this risk. ${ }^{5,15}$ In our current study, no teratomas formed within the brain during 12 weeks of posttransplantation follow-up evaluation.

\section{Migration of ESC-Derived Astrocytes Through Brain Parenchyma}

Astrocytes have a number of theoretical and practical advantages as gene therapy vectors within the CNS. The ability of transplanted astrocytes to migrate through the brain parenchyma could depend on a number of factors, including the age of the transplanted astrocytes, the age of the host, and the region into which the astrocytes are transplanted. In this study, we demonstrate that ESC-derived astrocytes have significant migratory capacity after allotransplantation into the white or gray matter, spreading to the contralateral hemisphere and into both gray and white matter at 6 weeks posttransplantation.

This migratory capacity is essential if ESC-derived astrocytes are to be used to deliver gene therapy to malignant gliomas, which have similar patterns of infiltration into the brain parenchyma. This broad migratory capacity would also be advantageous if ESC-derived astrocytes are to be used for gene therapy in diffuse astrocytic diseases like Alexander disease. ${ }^{9}$ Future studies will include determinations of whether culturing ESC-derived astrocytes for different periods of time affects migratory capacity. Recent evidence indicates that localized astrocytic dysfunction may contribute to mesial temporal lobe epilepsy. ${ }^{14}$ Trans- 

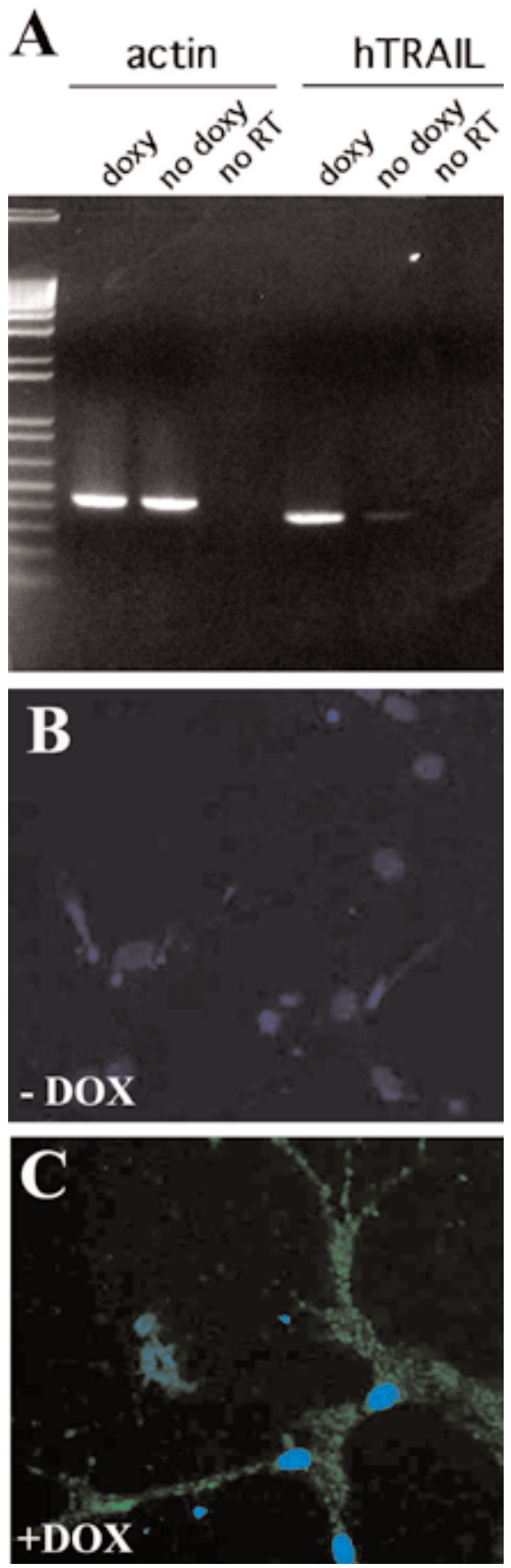

Fig. 1. Agarose gels and photomicrographs showing that the ESC-derived astrocytes express TRAIL. A: Results of RT-PCR analysis showing hTRAIL expression 24 hours after doxycycline (doxy, DOX) induction in TRAIL-expressing ESC-derived astrocytes. Actin and the absence of reverse transcriptase (no RT) are used as positive and negative controls, respectively. B and C: Immunofluorescent photomicrographs of TRAIL-expressing ESC-derived astrocytes before (B) and after (C) induction of doxycycline. Note the strong expression of TRAIL after doxycycline induction. Antibody visualization: Alexa 488 anti-mouse antibody. Original magnification $\times 20$ (B and C).
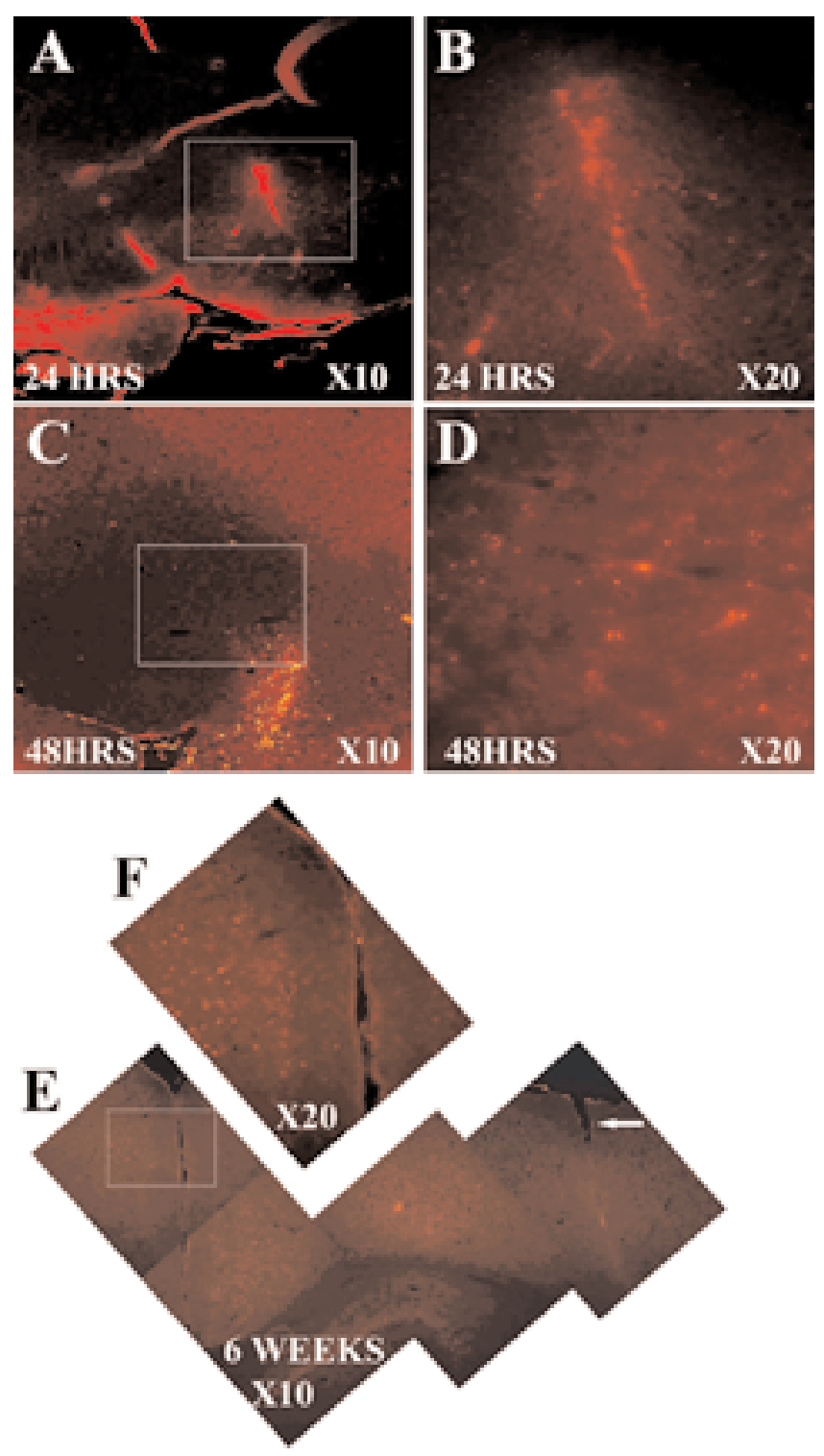

Fig. 2. Fluorescent photomicrographs of 10-micron-thick coronal mouse brain sections after transplantation of mouse ESC-derived astrocytes. A and B: Cells are still found in a clump 24 hours after grafting. (The box outlines the area of higher magnification shown in B.) $\mathrm{C}$ and D: Transplanted cells start migrating after 48 hours. (The box outlines the area of higher magnification shown in D.) E and F: A composite photomicrograph obtained 6 weeks after transplantation, showing the needle track (arrow) and the interhemispheric fissure (box). (The panel labeled $\mathrm{F}$ is a higher magnification of the area outlined by the box.) Note that multiple migratory fluorescent cells are seen in the contralateral hemisphere. Cells were tracked with a PKH26 fluorescent cell linker.

genic astrocytes that would remain close to the site of transplantation could be well suited for gene therapy of this condition, and for treatment of movement disorders requiring anatomically precisely placed gene therapy vectors.

Drug-Inducible Vectors for CNS Gene Therapy 

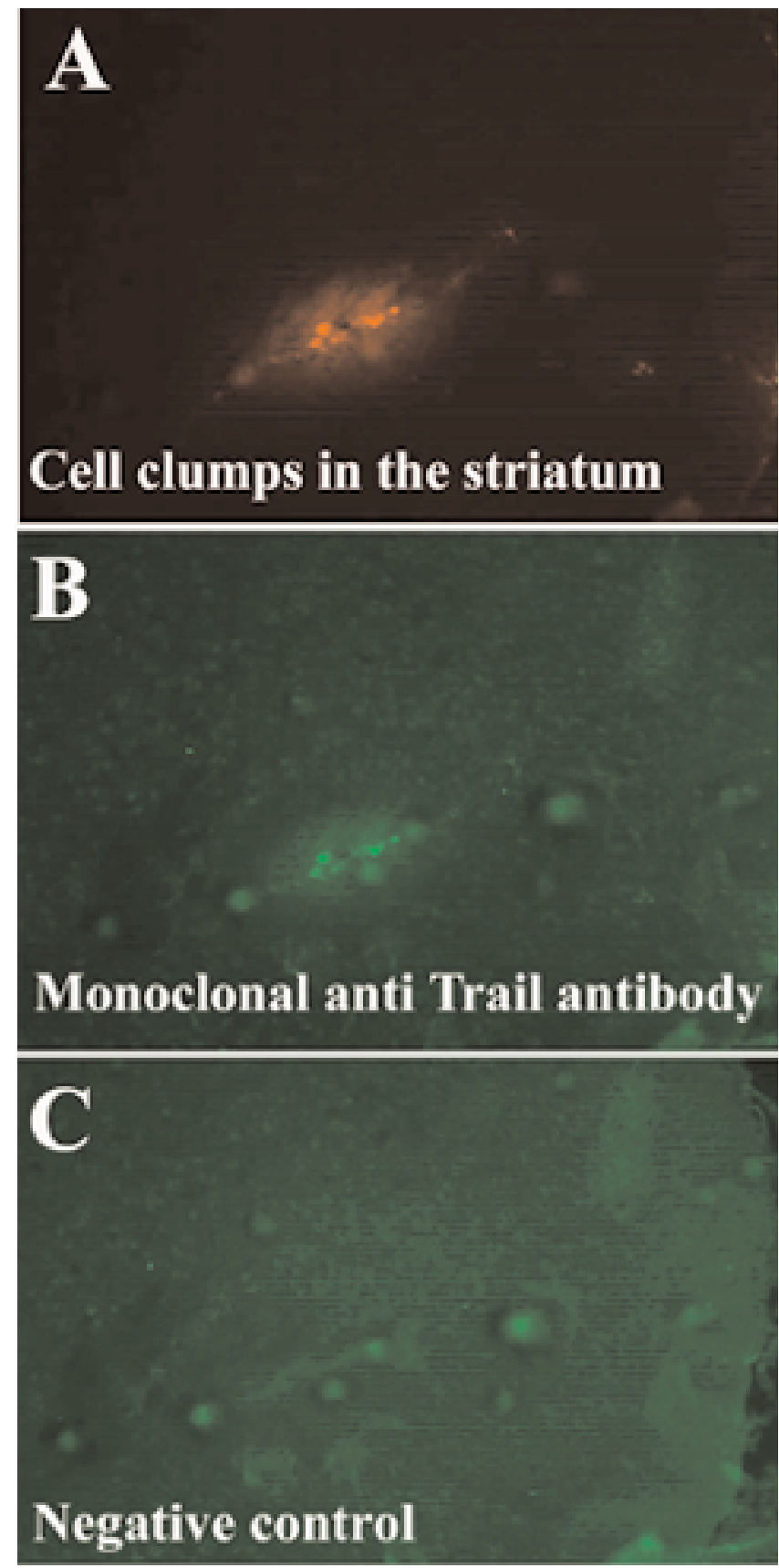

Fig. 3. Immunofluorescent photomicrographs of coronal 10micron-thick mouse brain sections obtained 48 hours after transplantation of ESC-derived astrocytes conditionally expressing TRAIL after administration of doxycycline. A: Red fluorescence for the cell tracker PKH26 fluorescent cell linker. B: Labeling with anti-TRAIL antibody. Visualization: Alexa 488 anti-mouse antibody. C: Omission of anti-TRAIL antibody. Note the strongly TRAIL-positive cells at the transplant site. Original magnification $\times 20$.

We show tightly regulated expression of an hTRAIL transgene by mouse ESC-derived astrocytes following allotransplantation into the brain. Although TRAIL has shown efficacy as an antitumor agent in animal models, its safety remains unproven. ${ }^{31}$ For TRAIL as well as for other thera- peutic genes, the use of inducible systems to regulate transgene expression will be important for safety as gene therapy strategies continue to move into clinical trials. In addition, gene therapy for degenerative CNS diseases may be most efficacious if the levels of expression of transgenes that affect production of neurotransmitters can be increased or decreased..$^{18}$ Insertion of transgene constructs into ESCs by using homologous recombination allows the production of large, clonal pools of cells, permitting testing and accurate prediction of the robustness and control of drug-inducible transgene expression prior to transplantation.

\section{CONCLUSIONS}

Strategies for the delivery of target gene/chemotherapeutic agents to these brain tumors are compromised by the invasive nature of the gliomas and the blood-brain barrier. Adenoviral vectors or convection-enhanced methods seem promising, although they have documented drawbacks. ${ }^{4,27,40}$ The migratory characteristics of ESC-derived astrocytes combined with the capability of carrying transgenes tightly regulated by external control shown in our study make ESC-derived astrocytes a promising new treatment modality for human malignant gliomas and other CNS diseases.

\section{References}

1. Aboody KS, Brown A, Rainov NG, et al: Neural stem cells display extensive tropism for pathology in adult brain: evidence from intracranial gliomas. Proc Natl Acad Sci USA 97: 12846-12851, 2000

2. Arnhold S, Lenartz D, Kruttwig K, et al: Differentiation of green fluorescent protein-labeled embryonic stem cell-derived neural precursor cells into Thy-1-positive neurons and glia after transplantation into adult rat striatum. J Neurosurg 93:1026-1032, 2000

3. Asano T, Ageyama N, Takeuchi K, et al: Engraftment and tumor formation after allogeneic in utero transplantation of primate embryonic stem cells. Transplantation 76:1061-1067, 2003

4. Ashkenazi A, Pai RC, Fong S, et al: Safety and antitumor activity of recombinant soluble Apo2 ligand. J Clin Invest 104: 155-162, 1999

5. Barberi T, Klivenyi P, Calingasan NY, et al: Neural subtype specification of fertilization and nuclear transfer embryonic stem cells and application in parkinsonian mice. Nat Biotechnol 21:1200-1207, 2003

6. Benedetti S, Pirola B, Pollo B, et al: Gene therapy of experimental brain tumors using neural progenitor cells. Nat Med 6: 447-450, 2000

7. Benveniste RJ, Keller G, Germano I: Embryonic stem cellderived astrocytes expressing drug-inducible transgenes: differentiation and transplantation into the mouse brain. J Neurosurg 103:115-123, 2005

8. Betchen SA, Kaplitt M: Future and current surgical therapies in Parkinson's disease. Curr Opin Neurol 16:487-493, 2003

9. Brenner M, Johnson AB, Boespflug-Tanguy O, et al: Mutations in GFAP, encoding glial fibrillary acidic protein, are associated with Alexander disease. Nat Genet 27:117-120, 2001

10. Brown AB, Yang W, Schmidt NO, et al: Intravascular delivery of neural stem cell lines to target intracranial and extracranial tumors of neural and non-neural origin. Hum Gene Ther 14: 1777-1785, 2003

11. Chen Y, Swanson RA: Astrocytes and brain injury. J Cereb Blood Flow Metab 23:137-149, 2003

12. Chiba S, Ikeda R, Kurokawa MS, et al: Anatomical and func- 
tional recovery by embryonic stem cell-derived neural tissue of a mouse model of brain damage. J Neurol Sci 219:107-117, 2004

13. Chiocca EA: Gene therapy: a primer for neurosurgeons. Neurosurgery 53:364-373, 2003

14. Eid T, Thomas MJ, Spencer DD, et al: Loss of glutamine synthetase in the human epileptogenic hippocampus: possible mechanism for raised extracellular glutamate in mesial temporal lobe epilepsy. Lancet 363:28-37, 2004

15. Erdo F, Buhrle C, Blunk J, et al: Host-dependent tumorigenesis of embryonic stem cell transplantation in experimental stroke. J Cereb Blood Flow Metab 23:780-785, 2003

16. Eriksson C, Ericson C, Gates MA, et al: Long-term, EGF-stimulated cultures of attached GFAP-positive cells derived from the embryonic mouse lateral ganglionic eminence: in vitro and transplantation studies. Exp Neurol 164:184-199, 2000

17. Espinosa-Jeffrey A, Becker-Catania SG, Zhao PM, et al: Selective specification of CNS stem cells into oligodendroglial or neuronal cell lineage: cell culture and transplant studies. J Neurosci Res 69:810-825, 2002

18. Georgievska B, Jakobsson J, Persson E, et al: Regulated delivery of glial cell line-derived neurotrophic factor into rat striatum, using a tetracycline-dependent lentiviral vector. Hum Gene Ther 15:934-944, 2004

19. Germano IM, Fable J, Gultekin SH, et al: Adenovirus/herpes simplex-thymidine kinase/gancyclovir complex: preliminary results of a phase I trial in patients with recurrent malignant gliomas. J Neurooncol 65:279-289, 2003

20. Hacein-Bey-Abina S, Von Kalle C, Schmidt M, et al: LMO2associated clonal $\mathrm{T}$ cell proliferation in two patients after gene therapy for SCID-X1. Science 302:415-419, 2003

21. Hao C, Beguinot F, Condorelli G, et al: Induction and intracellular regulation of tumor necrosis factor-related apoptosis-inducing ligand (TRAIL) mediated apoptosis in human malignant glioma cells. Cancer Res 61:1162-1170; 2001

22. Kagawa S, He C, Gu J, et al: Antitumor activity and bystander effects of the tumor necrosis factor-related apoptosis-inducing ligand (TRAIL) gene. Cancer Res 61:3330-3338, 2001

23. Kasuga C, Ebata T, Kayagaki N, et al: Sensitization of human glioblastomas to tumor necrosis factor-related apoptosis-inducing ligand (TRAIL) by NF-кB inhibitors. Cancer Sci 95:840-844, 2004

24. Keller G: Embryonic stem cell differentiation: emergence of a new era in biology and medicine. Genes Dev 19:1129-1155, 2005

25. Kyba M, Perlingeiro RC, Daley GQ: HoxB4 confers definitive lymphoid-myeloid engraftment potential on embryonic stem cell and yolk sac hematopoietic progenitors. Cell 109:29-37, 2002

26. Lee J, Elkahloun AG, Messina SA, et al: Cellular and genetic characterization of human adult bone marrow-derived neural stem-like cells: a potential antiglioma cellular vector. Cancer Res 63:8877-8889, 2003

27. McCormack MP, Rabbitts TH: Activation of the T-cell oncogene $L M O 2$ after gene therapy for X-linked severe combined immunodeficiency. N Engl J Med 350:913-922, 2004

28. McKay R: Stem cells-hype and hope. Nature 406:361-364; 2000
29. Murayama A, Matsuzaki Y, Kawaguchi A, et al: Flow cytometric analysis of neural stem cells in the developing and adult mouse brain. J Neurosci Res 69:837-847; 2002

30. Nakamizo A, Marini F, Amano T, et al: Human bone marrowderived mesenchymal stem cells in the treatment of gliomas. Cancer Res 65:3307-3318, 2005

31. Nitsch R, Bechmann I, Deisz RA, et al: Human brain-cell death induced by tumor-necrosis-factor-related apoptosis-inducing ligand (TRAIL). Lancet 356:827-828, 2000

32. Okano H: Stem cell biology of the central nervous system. J Neurosci Res 69:698-707; 2002

33. Park S, Lee KS, Lee YJ, et al: Generation of dopaminergic neurons in vitro from human embryonic stem cells treated with neurotrophic factors. Neurosci Lett 359:99-103, 2004

34. Paxinos G, Watson C: The Rat Brain in Stereotactic Coordinates. San Diego: Academic Press, 1986

35. Philips MF, Mattiasson G, Wieloch T, et al: Neuroprotective and behavioral efficacy of nerve growth factor-transfected hippocampal progenitor cell transplants after experimental traumatic brain injury. J Neurosurg 94:765-774, 2001

36. Poon Poon RY: Use of PKH membrane intercalating dyes to monitor cell trafficking and function, in Smith PM, DeMaggio S (eds): In Living Color: Flow Cytometry and Cell Sorting Protocols. New York: Springer-Verlag, pp 302-352

37. Rainov NG, Ren H: Clinical trials with retrovirus mediated gene therapy-what have we learned? J Neurooncol 65:227-236, 2003

38. Ridet JL, Sarkis C, Serguera C, et al: Transplantation of human adult astrocytes: efficiency and safety requirements for an autologous gene therapy. J Neurosci Res 72:704-708, 2003

39. Roth W, Isenmann S, Naumann U, et al: Locoregional Apo2L/ TRAIL eradicates intracranial human malignant glioma xenografts in athymic mice in the absence neurotoxicity. Biochem Biophys Res Commun 265:479-483, 1999

40. Saito R, Bringas JR, Panner A, et al: Convection-enhanced delivery of tumor necrosis factor-related apoptosis-inducing ligand with systemic administration of temozolomide prolongs survival in an intracranial glioblastoma xenograft model. Cancer Res 64:6858-6862, 2004

41. Sauer B, Henderson N: Site-specific DNA recombination in mammalian cells by the Cre recombinase of bacteriophage P1. Proc Natl Acad Sci USA 85:5166-5170, 1988

42. Selkirk SM, Greenberg SJ, Plunkett RJ, et al: Syngeneic central nervous system transplantation of genetically transduced mature, adult astrocytes. Gene Ther 9:432-443, 2002

43. Shah K, Hsich G, Breakefield XO: Neural precursor cells and their role in neuro-oncology. Dev Neurosci 26:118-130, 2004

44. Surawicz TS, Davis F, Freels S, et al: Brain tumor survival: results from the National Cancer Center Data Base. J Neurooncol 40:151-160; 1998

45. Sylvester KG, Longaker MT: Stem cells: review and update. Arch Surg 139:93-99, 2004

Manuscript received July 15, 2005.

Accepted in final form August 15, 2005.

Address reprint requests to: Isabelle Germano, M.D., Department of Neurosurgery, Mount Sinai School of Medicine, Annenberg 8-90, One Gustave Levy Place, New York, New York 10029. email: 